\title{
Seismic phases of 25 April 2015 (Mw 7.8) \\ Earthquake and 12 May 2015 (Mw 7.3) \\ Earthquake Predicted by AK135 Model - A comparison
}

\section{R. K. Tiwari and H. Paudyal}

Journal of Nepal Physical Society

Volume 7, Issue 2, June 2021

ISSN: 2392-473X (Print), 2738-9537 (Online)

Editors:

Dr. Binod Adhikari

Dr. Bhawani Joshi

Dr. Manoj Kumar Yadav

Dr. Krishna Rai

Dr. Rajendra Prasad Adhikari

Mr. Kiran Pudasainee

JNPS, 7 (2), 58-64 (2021)

DOI: https://doi.org/10.3126/jnphyssoc.v7i2.38623

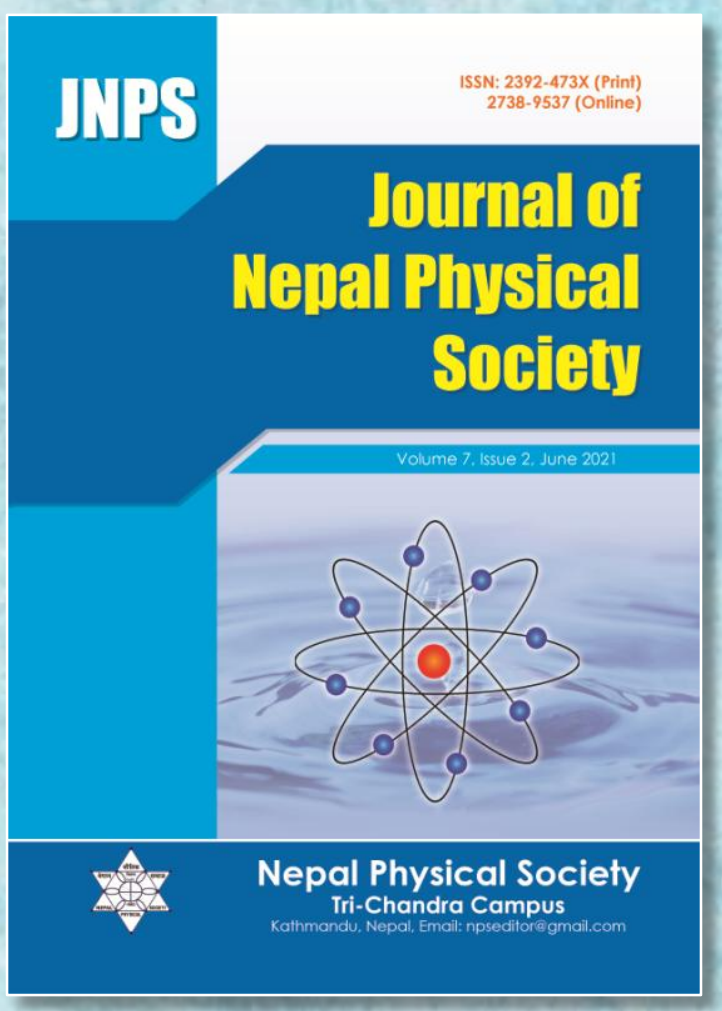

Published by:

Nepal Physical Society

P.O. Box: 2934

Tri-Chandra Campus

Kathmandu, Nepal

Email: nps.editor@gmail.com 


\title{
Seismic phases of 25 April 2015 (Mw 7.8) Earthquake and 12 May 2015 (Mw 7.3) Earthquake Predicted by AK135 Model - A comparison
}

\author{
R. K. Tiwari ${ }^{1,2,{ }^{*}}$ and H. Paudyal ${ }^{2}$ \\ ${ }^{1}$ Central Department of Physics, Tribhuvan University, Kirtipur, Kathmandu \\ ${ }^{2}$ Birendra Multiple Campus, Tribhuvan University, Bharatpur, Chitwan \\ * Corresponding Email: ram.tiwari@bimc.tu.edu.np
}

Received: 09 April, 2021; Revised: 10 May, 2021; Accepted: 22 June, 2021

\begin{abstract}
A strong Mw 7.8 (depth $=8.2 \mathrm{~km}$ ) earthquake initiated $\sim 80 \mathrm{~km}$ northwest of the Kathmandu on 25 April of 2015 was followed by the Mw 7.3 (depth = $15 \mathrm{~km}$ ) earthquake on 12 May. The seismic phases of these earthquakes were predicted at Kakani, Kathmandu seismic station $\left(27.80^{\circ} \mathrm{N}\right.$ and $\left.85.28^{\circ} \mathrm{E}\right)$ using software model AK135. The model predicts 21 arrivals for Gorkha earthquake with first $p$ phase arriving at incident angle $82.65^{\circ}$ in 11.516 seconds and final phase SKIKSSKIKS in 3270.791 seconds with incident angle $0.02^{\circ}$. Similarly, for the Dolakha earthquake 27 arrivals are predicted with the first arrival p phase at incident angle $74.35^{\circ}$ in 14.504 seconds and final arrival SKIKSSKIKS phase at incident angle $0.03^{\circ}$ in 3268.823 seconds. The 5 depth phases and 8 core phases predicted are similar for both the earthquakes while 8 and 12 mantle phases are predicted for Gorkha earthquake and Dolakha earthquake respectively. In addition, two crustal phases ( $\mathrm{Pn}, \mathrm{Sn}$ ) were predicted only for Dolakha earthquake. The additional phases are critically refracted seismic phases indicating the existence of the Moho discontinuity between the crust and upper mantle. Their existence for Dolakha earthquake could be the indication of different geological provinces of the source region of the earthquakes, differing in age, crustal thickness, temperature, and tectonic stress. The ratio of $\mathrm{P}$ wave ad $\mathrm{S}$ wave velocity is found to be 1.67 for the regions. These seismic phases reflect their sensitivity to different layers of the earth and carry information about the geometrical and physical properties of discontinuities inside the earth.
\end{abstract}

Keywords: Crustal phase, Mantle phase, Core phase, Depth phase, AK135.

\section{INTRODUCTION}

On 25 April 2015 11:56 am local time (06:11:26 UTC), Gorkha region, the central Himalayan region was hit by a devastating earthquake of momentmagnitude $\mathrm{M}_{\mathrm{w}} 7.8\left(28.23^{\circ} \mathrm{N}, 84.73^{\circ} \mathrm{E}\right)$ and just after 18 days, another large earthquake of $\mathrm{M}_{\mathrm{w}} 7.3$ occurred at Dolakha $\left(27.80^{\circ} \mathrm{N}, 86.06^{\circ} \mathrm{E}\right)$, about $140 \mathrm{~km}$ away from the epicenter of the mainshock [1]. These two-earthquake doublet effectively unfastened a $\sim 160 \mathrm{~km}$ along- strike length at the lower edge of the locked portion of the Main Himalayan Thrust (MHT) beneath central Nepal [2]. The seismic activity of the region is dominated by three major fault systems, namely the Main Central Thrust (MCT), Main Boundary Thrust
(MBT) and Main Frontal Thrust (MFT) (Figure 1). The MHT is the root detachment of these major faults. Both the MFT and MBT sole into the MHT. The MHT accommodates crustal shortening of India and Eurasia as a result of the ongoing collision between the Indian and Eurasian plates [3]. The Gorkha earthquake is the largest earthquake occurring on the MHT since the great 1934 Bihar-Nepal earthquake Mw 8.1 [4].

Seismic waves from earthquake hypocenter travel through different layers of Earth. They have nonstationary amplitude and the energy associated with the signal is high at the beginning and decay at the end. This results different types of seismic waves at different time-instants and phenomenon of 
distribution [5]. The body waves (the $\mathrm{P}$ and $\mathrm{S}$ waves) from source are reflected or refracted and also get converted into other phases as they encounter boundary between two layers [6]. These waves can be recorded by seismographs and are useful for velocity and geological structure study of earth's interior [7].

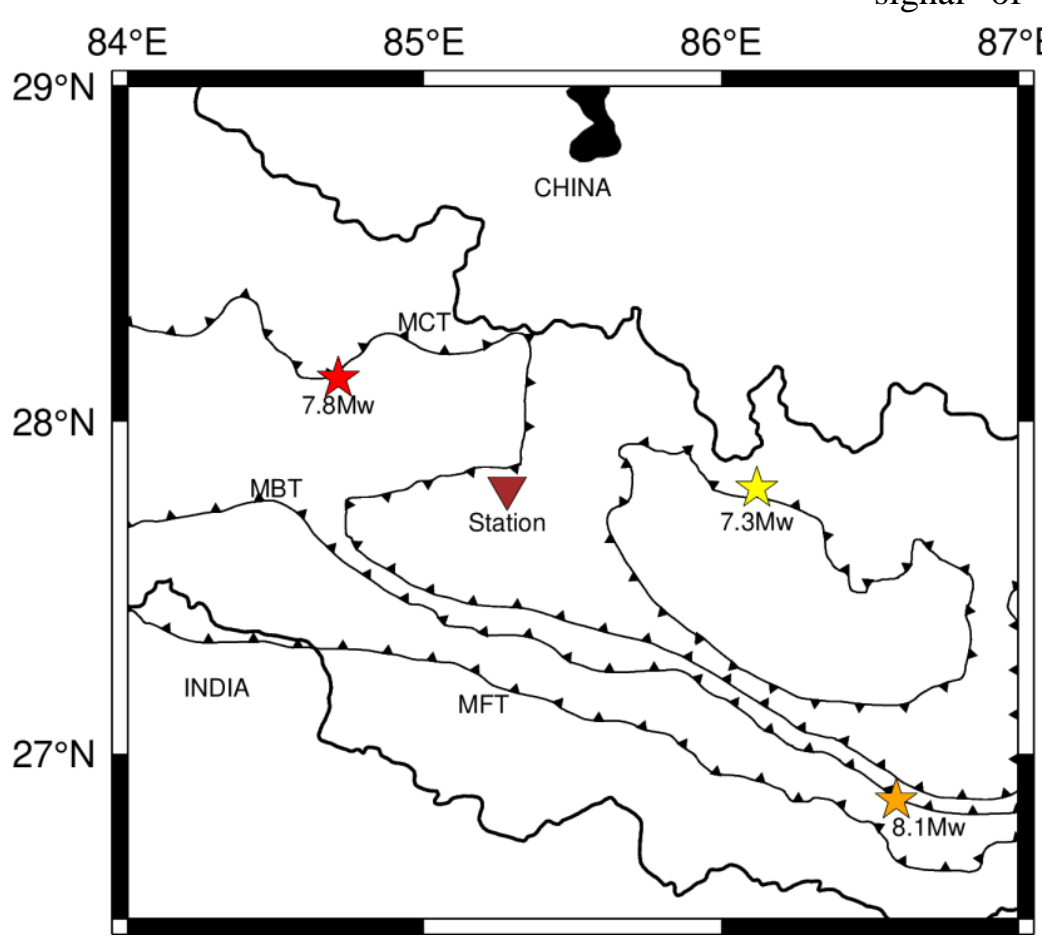

characteristics of seismic wave signal can be used to study ground motion during earthquake. Based on wavelet transform, the ground motion in Kathmandu valley is estimated [5] and the high amplitude signals are found associated with the horizontal motion with the release of high energy. Similarly, from the multifractal study of seismic signal was noticed with growing distances and the time duration of main event was noticed to be very short [9]. A group of researchers [10] studied the finite rupture processes and the associated 3D ground motion of the Gorkha earthquake and Dolakha earthquake and concluded that the different rupture features between these events could be related to difference in fault zone structure. Our study aims at adding information about the path traces by seismic wave for their journey from earthquake focus to seismic station. For this, we examine the propagation of seismic wave phases of aforementioned two events predicted by simulation model AK135 [11].

\section{METHODOLOGY}

Fig. 1: The tectonic background and locations of two large 2015 Nepal earthquakes, i.e., the Mw 7.8 Gorkha earthquake (left-hand red star) and Mw 7.3 Dolakha earthquake (right-hand yellow star), with 1934 BiharNepal earthquake Mw 8.1 by orange star on bottom right corner. Brown delta shows Kakani, Kathmandu seismic station.

The seismic phases generated by an earthquake at a shallow depth $(\mathrm{d}<10 \mathrm{~km})$ and recorded by a station within a few $\mathrm{km}$ of the epicenter, are generally identified as direct $\mathrm{P}$ and $\mathrm{S}$ arrivals. With growing distance more and more secondary seismic body-wave phases are appeared following the direct $\mathrm{P}$-wave and S-wave arrivals in seismic records [8]. Knowing the distance from the epicenter and the arrival times of the different waves, information on the structure of the Earth's interior and composition of Earth's layers can be inferred. The proper identification and complementary use of secondary phases significantly improves the precision and accuracy of seismic event locations, their source depth in particular. The time frequency
There are two default models available for the simulation of travel times. The first one, the International Association of Seismology and Physics of the Earth's Interior (IASP91), developed by Kennett and Engdahl [11] and the second one is a modern global Earth model AK135 developed by Kennett et al. [12]. The AK135 represents an update of the IASP91 model and attempts to match the behavior of a wider range of seismic phases. The model AK135 is the global 1-D earth velocity model that assumes a homogeneous $35 \mathrm{~km}$ thick two-layer crust with the intermediate crustal discontinuity at $20 \mathrm{~km}$ depth. The AK135 model was developed with a continental style for the uppermost crust and upper mantle so, it is suitable for the study of continental earthquakes in the Himalayan region [13].

\section{RESULTS AND DISCUSSION}

The different arrivals phases with their characteristics, predicted by the model, for Gorkha earthquake and Dolakha earthquake are presented in Table 1 and Table 2. 
Table 1: Twenty-one seismic phases with arrival time and incident angle for Gorkha earthquake

\begin{tabular}{llllllll}
\hline S.N. & $\begin{array}{l}\text { Phase } \\
\text { name }\end{array}$ & $\begin{array}{l}\text { Arrival } \\
\text { Time }(\mathbf{S})\end{array}$ & $\begin{array}{l}\text { Incident } \\
\text { Angle }\left(^{\circ}\right)\end{array}$ & S.N. & $\begin{array}{l}\text { Phase } \\
\text { name }\end{array}$ & $\begin{array}{l}\text { Arrival } \\
\text { Time }(\text { S) }\end{array}$ & $\begin{array}{l}\text { Incident } \\
\text { Angle }\left(^{\circ}\right)\end{array}$ \\
\hline 1 & $\mathrm{p}$ & 11.516 & 82.65 & 12 & PKiKP & 993.373 & 0.04 \\
2 & $\mathrm{P}$ & 12.660 & 62.81 & 13 & pPKiKP & 996.201 & 0.04 \\
3 & $\mathrm{P}$ & 12.664 & 64.13 & 14 & sPKiKP & 997.157 & 0.04 \\
4 & $\mathrm{sP}$ & 13.337 & 89.72 & 15 & SKIKP & 1204.466 & 0.04 \\
5 & $\mathrm{~s}$ & 19.304 & 82.65 & 16 & PKIKKIKP & 2123.928 & 0.04 \\
6 & $\mathrm{~S}$ & 21.227 & 63.62 & 17 & SKIKKIKP & 2122.971 & 0.04 \\
7 & $\mathrm{~S}$ & 21.228 & 64.13 & 18 & PKIKKIKS & 2123.928 & 0.02 \\
8 & $\mathrm{PcP}$ & 510.277 & 0.17 & 19 & SKIKKIKS & 2335.020 & 0.02 \\
9 & $\mathrm{ScP}$ & 721.375 & 0.22 & 20 & PKIKPPKIKP & 2423.552 & 0.05 \\
10 & $\mathrm{PcS}$ & 722.331 & 0.13 & 21 & SKIKSSKIKS & 3270.791 & 0.02 \\
11 & $\mathrm{ScS}$ & 933.433 & 0.18 & & & & \\
\hline
\end{tabular}

Table 2: Twenty-seven seismic phases with arrival time and incident angle for Dolakha earthquake

\begin{tabular}{llllllll}
\hline S.N. & $\begin{array}{c}\text { Phase } \\
\text { name }\end{array}$ & $\begin{array}{c}\text { Arrival } \\
\text { Time }(\mathbf{S})\end{array}$ & $\begin{array}{c}\text { Incident } \\
\text { Angle }\left({ }^{\circ}\right)\end{array}$ & $\begin{array}{l}\text { S.N. } \\
\text { name }\end{array}$ & $\begin{array}{c}\text { Phase } \\
\text { namal Time } \\
(\text { S) }\end{array}$ & $\begin{array}{c}\text { Incident } \\
\text { Angle }\left(^{\circ}\right)\end{array}$ \\
\hline 1 & $\mathrm{p}$ & 14.504 & 74.35 & 15 & $\mathrm{ScP}$ & 719.422 & 0.27 \\
2 & $\mathrm{P}$ & 14.666 & 62.81 & 16 & $\mathrm{PcS}$ & 721.171 & 0.17 \\
3 & $\mathrm{P}$ & 14.900 & 72.84 & 17 & $\mathrm{ScS}$ & 931.485 & 0.24 \\
4 & $\mathrm{P}$ & 15.970 & 45.84 & 18 & PKiKP & 992.203 & 0.05 \\
5 & $\mathrm{Pn}$ & 15.970 & 45.84 & 19 & pPKiKP & 997.375 & 0.05 \\
6 & $\mathrm{P}$ & 16.048 & 50.39 & 20 & sPKiKP & 999.124 & 0.05 \\
7 & $\mathrm{sP}$ & 17.766 & 89.68 & 21 & SKiKP & 1202.503 & 0.05 \\
8 & $\mathrm{~S}$ & 24.313 & 63.62 & 22 & PKIKKIKP & 1910.704 & 0.05 \\
9 & $\mathrm{~S}$ & 24.644 & 72.84 & 23 & SKIKKIKP & 2121.004 & 0.05 \\
10 & $\mathrm{~S}$ & 24.976 & 75.06 & 24 & PKIKKIKS & 2122.753 & 0.03 \\
11 & $\mathrm{~S}$ & 27.009 & 50.18 & 25 & SKIKKIKS & 2323.053 & 0.03 \\
12 & $\mathrm{Sn}$ & 27.009 & 50.18 & 26 & PKIKPPKIKP & 2422.377 & 0.07 \\
13 & $\mathrm{~S}$ & 27.012 & 50.75 & 27 & SKIKSSKIKS & 3268.823 & 0.03 \\
14 & $\mathrm{PcP}$ & 509.115 & 0.21 & & & & \\
\hline
\end{tabular}

Seismic phases for the Gorkha earthquake (depth $8.2 \mathrm{~km}$ ) with their properties are listed in Table 1 and depicted in the Figure 2 and Figure 3. The model predicts 21 seismic phases for Gorkha earthquake including 8 mantle phases, 5 depth phases and 8 core phases.

- The seismic ray path $\mathrm{p}$ (Lower case letter) indicates pressure $(\mathrm{P})$ wave travelling directly from an earthquake focus to the station (Figure 2).

- P (Upper case letter) indicate a P wave travelling down from the focus, reflected from the upper crust (depth 20 km), which then travelled to station as $\mathrm{P}$ wave.

- Second upper-case letter P indicate a $\mathrm{P}$ wave travelling down from the focus, travelled along the upper crust and reflected from the upper crust (depth $20 \mathrm{~km}$ ), which then travelled to station as $\mathrm{P}$ wave.

- The lower-case letter $p$ is the relatively short upgoing leg of $\mathrm{P}$ phases.

- The seismic phase sP in the sequence sP, s, S, S (Figure 3) is an $\mathrm{S}$ wave that started out upward from the source as s, reflected off the earth's surface and converted to a $\mathrm{P}$ wave which then travelled to the station as a $\mathrm{P}$ wave.

- The seismic wave s (Lower case letter) indicates shear wave (S) wave travelling directly towards the station. 
- Seismic phase S (upper case) travels downwards from an earthquake focus, reflected from the upper crust $(\sim 20 \mathrm{~km})$, which then travelled to station as $\mathrm{S}$ wave.

- Second upper-case letter $S$ in the sequence indicates seismic phase that travels downwards from an earthquake focus, travelled along the upper crust $(\sim 20 \mathrm{~km})$, which then reflected to station as $\mathrm{S}$ wave.

For Gorkha earthquake, the $\mathrm{P}$ wave velocity $\left(\mathrm{V}_{\mathrm{P}}\right)$ is calculated as $5.75 \mathrm{kms}^{-1}$ and $\mathrm{S}$ wave velocity $\left(\mathrm{V}_{\mathrm{S}}\right)$ is calculated as $3.43 \mathrm{kms}^{-1}$. Therefore, the ratio of these crustal $\mathrm{P}$ wave velocity to the $\mathrm{S}$ wave velocity $\left(V_{P} / V_{S}\right)$ is 1.67 .

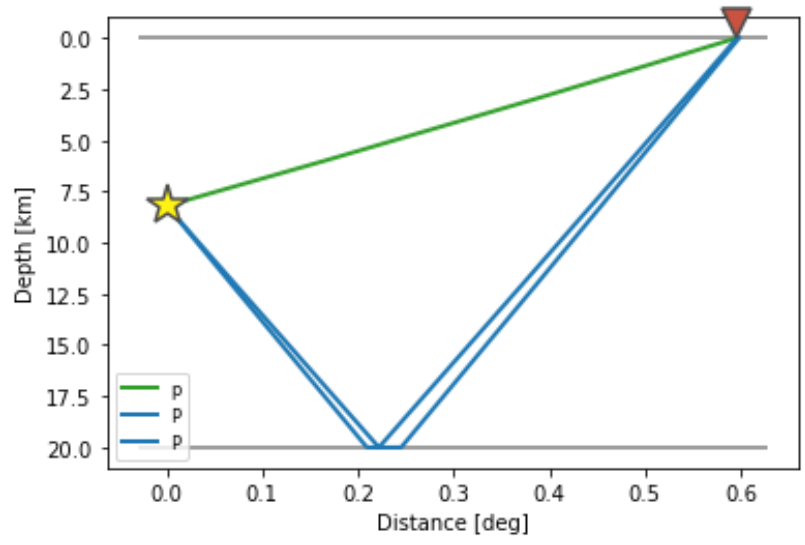

Fig. 2: Seismic ray path of phases $p, P, P$ of Gorkha earthquake where yellow star is for the earthquake focus and brown delta is for seismic station.

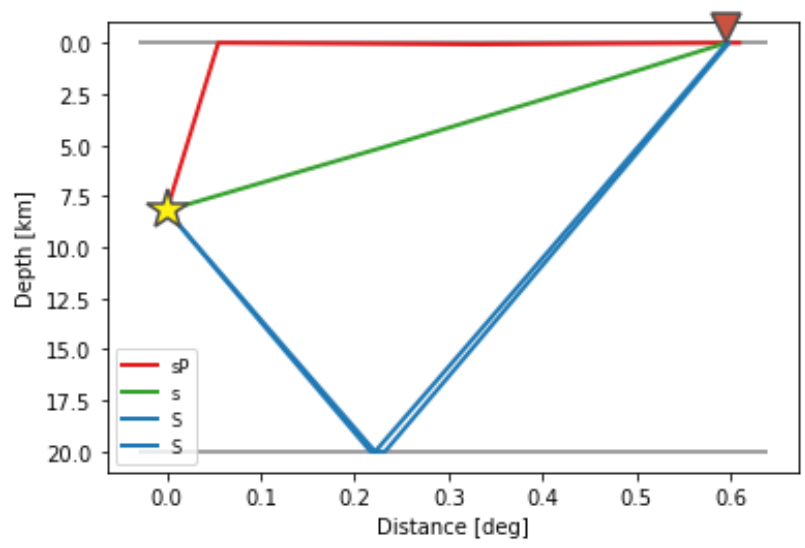

Fig. 3: Seismic ray path of phases sP, s, S, S of Gorkha earthquake where yellow star is for the earthquake focus and brown delta is for seismic station.

Seismic phases for the Dolakha earthquake (depth $15 \mathrm{~km}$ ) with their properties are listed in Table 2 and depicted in the Figure 4 and Figure 5. The model predicts 27 seismic phases for Dolakha earthquake including 2 crustal phases, 12 mantle phases, 5 depth phases and 8 core phases.

- The lower-case letter $p$ in sequence $p, P, P, P$, $\mathrm{Pn}, \mathrm{P}$ indicates longitudinal or pressure $(\mathrm{P})$ wave travelling directly towards the station from an earthquake focus

- The first upper-case letter P (Figure 4) indicate a $\mathrm{P}$ wave travelling down from the focus, reflected from the upper crust (depth $20 \mathrm{~km}$ ), which then travelled to station as $\mathrm{P}$ wave.

- The second upper case letter P indicate a P wave travelling down from the focus, travelled along the upper crust, reflected from the upper crust (depth 20km), which then travelled to station as $P$ wave.

- The third upper case letters $\mathrm{P}$ in the sequence indicates $\mathrm{P}$ wave travelling downwards from the focus, refracted from depth $\sim 20 \mathrm{~km}$ and then reflected form the crust mantle boundary (Moho) at $\sim 35 \mathrm{~km}$ depth which then travelled towards the station.

- The Pn is compressional or shear wave travelling along (just beneath) the Moho discontinuity called head wave. The Pn phase is a mantle lid guided wave and it is the first phase to arrive when the distance between a station and an earthquake exceeds about $150 \mathrm{~km}$ in continental regions with a Moho depth of about $35 \mathrm{~km}$ [14]. The head wave $\mathrm{Pn}$ is followed by the larger and sharper impulse of short period direct $P[15,16]$ (Figure 4).

- In the sequence sP, s, S, S, S, Sn, S (Figure 5) the seismic phase $\mathrm{SP}$ is an $\mathrm{S}$ wave that started out upward from the source (s), reflected off the earth's surface and also converted to a $\mathrm{P}$ wave which then travelled to the station as a $\mathrm{P}$ wave $(\mathrm{P})$.

- The lower-case letter $\mathrm{s}$ indicates shear wave (S) travelling directly from an earthquake focus towards the station.

- The first upper-case letter $S$ in the sequence indicate shear wave travelling down from the focus, reflected from the upper crust $(\sim 20 \mathrm{~km})$, which then travelled to station as $\mathrm{S}$ wave.

- The second letter $S$ indicate shear wave travelling down form the focus, travel along the upper crust (depth $\sim 20 \mathrm{~km}$ ) which then travelled to station as $\mathrm{S}$ wave.

- The third upper case letter $S$ in the sequence indicates shear wave travelling down from the focus, refracted from the upper crust $(\sim 20 \mathrm{~km})$, 
and reflected from Moho $(\sim 35 \mathrm{~km})$ which then travelled to station as $\mathrm{S}$ wave.

- The seismic phase $\mathrm{Sn}$ indicates seismic wave bottoming from the focus which then reflected from the Earth's uppermost mantle towards station [17]. The head wave $(\mathrm{Sn})$ is followed by the larger and sharper impulse of short period direct $S$ [16].

For Dolakha earthquake, the $\mathrm{P}$ wave velocity $\left(\mathrm{V}_{\mathrm{P}}\right)$ is calculated as $5.70 \mathrm{kms}^{-1}$ and $\mathrm{S}$ wave velocity $\left(\mathrm{V}_{\mathrm{S}}\right)$ is calculated as $3.40 \mathrm{kms}^{-1}$. Therefore, the ratio of these crustal $\mathrm{P}$ wave velocity to the $\mathrm{S}$ wave velocity $\left(V_{P} / V_{S}\right)$ is 1.67 . The previous studies in the Himalayan region [18] estimated the ratio $\left(V_{P} / V_{S}\right)$ to be 1.73. The $\mathrm{P}$ wave velocity $5.7 \mathrm{kms}^{-1}$ and $\mathrm{S}$ wave velocity $3.6 \mathrm{kms}^{-1}(\leq 23 \mathrm{~km})$ were noted for the crust below Nepal [19] giving velocity ratio 1.60 . So, the velocity calculated by the model considered in this study is in agreement with previous findings.

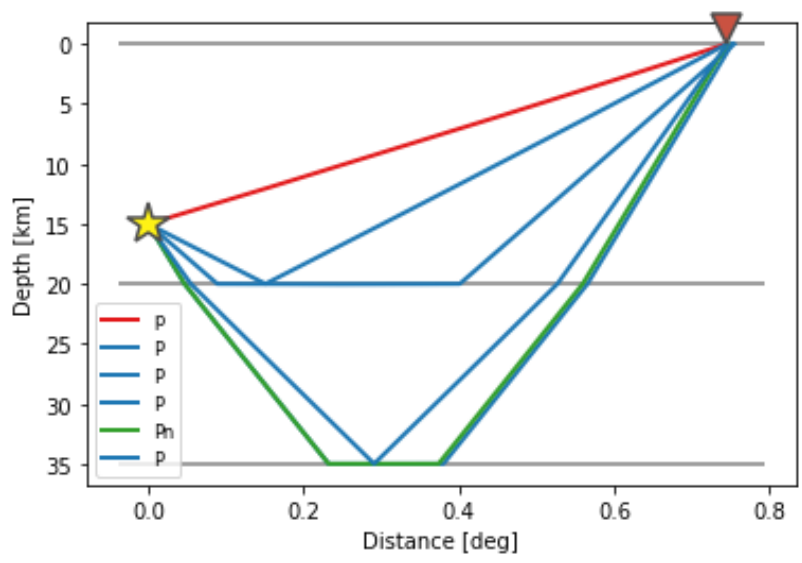

Fig. 4: Seismic ray path of phases $p, P, P n$ of Dolakha earthquake where yellow star is for the earthquake focus and brown delta is for seismic station.

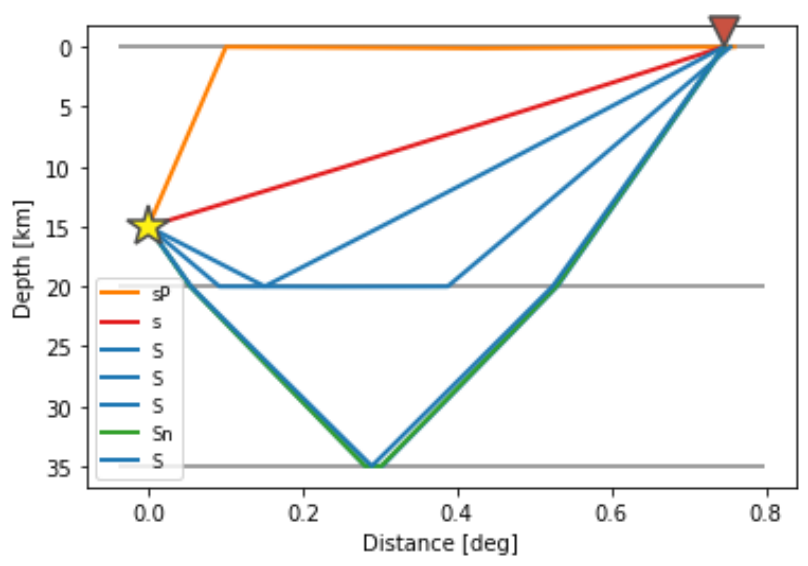

Fig. 5: Seismic ray path of phases $s P, s, S, S n$ of Dolakha earthquake where yellow star is for the earthquake focus and brown delta is for seismic station.
In addition, in the seismic phases $\mathrm{PcP}, \mathrm{ScP}, \mathrm{PcS}$ and $\mathrm{ScS}$ (observed for both earthquakes) symbols $\mathrm{c}$ indicates upward reflections from the outer side of the core mantle boundary (CMB) so the phase PcP indicates $\mathrm{P}$ reflection from the $\mathrm{CMB}, \mathrm{ScP}$ indicates $\mathrm{S}$ to $\mathrm{P}$ converted reflection from $\mathrm{CMB}, \mathrm{PcS}$ indicates $\mathrm{P}$ to $\mathrm{S}$ converted reflection from the $\mathrm{CMB}$, while $\mathrm{ScS}$ is for $\mathrm{S}$ reflection from the CMB. Thus, the phases $\mathrm{P}, \mathrm{S}, \mathrm{PcP}, \mathrm{ScP}, \mathrm{PcS}$ and $\mathrm{ScS}$ are mantle seismic phases. In the phases like PKiKP, PKIKP etc. the symbol $\mathrm{K}$ is longitudinal wave which has traveled through the Earth's outer core, I is longitudinal wave which has traveled through the Earth's inner core and i indicates upward reflection from inner core boundary (ICB) so the phase PKiKP is the wave reflected at ICB while the phase PKIKP is a pure refracted longitudinal wave from outermost part of the inner core. It has travelled the first part of its path as $\mathrm{P}$ through crust and mantle, the second through the outer core, the third through the inner core, and the fourth and fifth parts back again through outer core and mantle/crust. These two are core phases along with six others (Table 1 and Table 2). The phases $\mathrm{p}, \mathrm{s}, \mathrm{sP}, \mathrm{pPKiKP}$ and sPKiKP are depth phases. The phases Pn and Sn are $P$ wave and $S$ wave bottoming in the uppermost mantle and are crustal phases [20]. Seismic wave phases $\mathrm{Pn}$ and $\mathrm{Sn}$ are essential in exploring regional crustal and mantle lid structure and rheology [21].

The seismic phases listed for Gorkha earthquake (epicenter distance $\sim 66.18 \mathrm{~km}$ from the station) and for Dolakha earthquake (epicenter distance $\sim 82.73$ $\mathrm{km}$ from the station) in this work are found to travel through crust and uppermost mantle. According to Bormann et al. [22] seismic waves arriving at stations at local distances of up to about $150 \mathrm{~km}$ from the seismic source have traveled exclusively through the crust or the sub-crustal uppermost mantle. Thus, the seismic wave predicted by the Ak135 model in this work is in agreement with the observed seismic phases.

\section{CONCLUSION}

Various direct, reflected and converted seismic phases have been predicted for Gorkha earthquake and Dolakha earthquake at Kakani, Kathmandu, Nepal seismic station using TauPy Model (AK135). The ray-geometry as illustrated in Figure $(2,3,4,5)$ show the existence of three primary travel paths between the source and the station: (i) direct arrival $\mathrm{p}, \mathrm{s}$ (both lower case) which travels in a straight line connecting the source and receiver, (ii) 
reflected arrivals and (iii) head waves. Additional rays involving multiple reflections are also predicted by the model. The crustal phases (Pn and Sn) predicted only for Dolakha earthquake indicates geological provinces that differ in age, crustal thickness (pressure), heat flow (temperature), and tectonic regime (stress) [23]. Their existence could also be the indication of difference in fault zone structure of these two earthquakes [10]. The ratio of $\mathrm{P}$ wave velocity to the $\mathrm{S}$ wave velocity is found to be 1.67 for the regions. Seismic waves predicted at Kakani station from the two earthquake sources have found travelled dominatingly through the crust or the subcrustal uppermost mantle. Identification of these phases on seismogram is importance for a better event location, and improved source depth in particular [24, 25].

\section{Software resources}

The plots were made using Obspy-A Python Tool Box for Seismology [26] and Generic Mapping Tools (GMT) [27]

\section{ACKNOWLEDGEMENTS}

One of the authors RKT would like to acknowledge Tribhuvan University for providing sabbatical leave and University Grants Commission (UGC), Nepal for providing financial support in the form of fellowship.

\section{REFERENCES}

[1] Thapa, D. R.; Tao, X.; Fan, F. and Tao, Z. Aftershock analysis of the 2015 Gorkha-Dolakha (Central Nepal) earthquake doublet, Heliyon, 4:e0068 (2018).

[2] Mendoza, M. M.; Ghosh, A.; Karplus, M. S.; Klemperer, S. L.; Sapkota, S. N.; Adhikari, L. B. and Velasco, A. Duplex in the Main Himalayan Thrust illuminated by aftershocks of the $2015 M_{\mathrm{w}}$ 7.8 Gorkha earthquake, Nature Geoscience, 12:1018-1022 (2019).

[3] Hubbard, J.; Almeida R.; Foster, A.; Sapkota, S. N.; Bürgi, P. and Tapponnier P. Structural segmentation controlled the $2015 \mathrm{M}_{\mathrm{w}} 7.8$ Gorkha earthquake rupture in Nepal, Geology, 44: 639642 (2016).

[4] Sapkota, S. N.; Bollinger, L. and Perrier, F. Fatality rates of the $\mathrm{Mw} \sim 8.2,1934$, Bihar-Nepal earthquake and comparison with the April 2015 Gorkha earthquake, Earth, Planets and Space, 68:40 (2016)

[5] Adhikari, B.; Dahal, S.; Karki, M.; Mishra, R. K.; Dahal, R. K.; Sasmal, S. and Klausner, V. Application of wavelet for seismic wave analysis in Kathmandu Valley after the 2015 Gorkha earthquake, Nepal, Geoenvironmental Disaster, 7, (2020).

[6] Letort, J.; Bollinger L.; Lyon-Caen, H.; Guilhem, A.; Cano, Y.; Baillard, C. and Adhikari, L.B. Teleseismic depth estimation of the 2015 Gorkha-Nepal aftershocks, Geophysical Journal International, 207:1584-1595 (2016).

[7] Romanowicz, B. Using seismic waves to image Earth's internal structure, Nature, 451:266-268 (2008).

[8] Sato, H. and Fehler, M. C. Seismic wave propagation and scattering in the heterogeneous Earth, Springer-Verlag, New York (1998).

[9] Tiwari, B. R.; Xu, J.; Adhikari, B. and Chapagain, N. P. Multifractal analysis for seismic wave in Kathmandu valley after Gorkha Earthquake-2015, Nepal, Journal of Nepal Physical Society, 6:113120 (2020).

[10] Wei, S.; Chen, M.; Wang, X.; Graves, R.; Lindsey, E.; Wang, T. and Helmberger, D. The 2015 Gorkha (Nepal) earthquake sequence: I. Source modeling and deterministic 3D ground shaking. Tectono Physics, 722, 447-461(2018).

[11] Kennett, B. L. N. and Engdahl, E. R. Travel times for global earthquake location and phase identification, Geophysical Journal International, 122:429-465 (1991).

[12] Kennet, B. L. N.; Engdahl, E. R. and Buland, R. Constraints on seismic velocities in the Earth from travel times, Geophysical Journal International, 122:108-124 (1995).

[13] Engdahl, E. R.; van der Hilst, R. and Buland, R. Global teleseismic earthquake relocation with improved travel times and procedures for depth determination, Bulletin of Seismological Society of America, 88:722-743 (1998).

[14] Khaled Al-D.; Sandvol E.; Al-Lazki A. and Barazangi M. Regional seismic wave propagation ( $\mathrm{Lg}$ and $\mathrm{Sn}$ ) and $\mathrm{Pn}$ attenuation in the Arabian Plate and surrounding regions, Geophysical Journal International, 157:775-795 (2004).

[15] Chaklader, A. The Mohorovicic discontinuity, Nature, 207:1082-1083 (1965).

[16] Kulhanek, O. Anatomy of Seismograms, Elsevier, Amsterdam, New York, 178 (1990).

[17] Cook, K. L.; Algermissen, S.T. and Costain, J. L. The status of Ps converted waves in crustal studies. Journal of Geophysical Research, 67:4769-4778 (1962)

[18] Monsalve, G.; Sheehan A.; Schulte-Pelkum, V.; Rajaure, S.; Pandey, M. R. and Wu, F. Seismicity and one dimensional velocity structure of the Himalayan collision zone: Earthquakes in the crust and upper mantle, Journal of Geophysical Research, 111:B10301 (2006). 
[19] McNamara, D.E.; Yeck, W.L.; Barnhart, W.D.; Schulte-Pelkum, V.; Bergman, E.; Adhikari, L.B.; Dixit, A.; Hough, S.E.; Benz, H.M. and Earle, P.S. Source modeling of the $2015 \mathrm{Mw} 7.8 \mathrm{Nepal}$ (Gorkha) earthquake sequence: Implications for geodynamics and earthquake hazards, Tectonophysics, 714-715: 21-30 (2016).

[20] Storchak, D. A.; Schweitzer J. and Bormann P. The IASPEI Standard Seismic Phase List, Seismological Research Letters, 74: 761-772 (2003).

[21] Chiu, K., and Snyder, D. B. Regional seismic wave propagation ( $\mathrm{Lg} \& \mathrm{Sn}$ phases) in the Amerasia Basin and High Arctic, Polar Science, 9:130-145 (2015).

[22] Bormann, P.; Engdahl, B. and Kind, R. Seismic wave propagation and earth models, in New Manual of Seismological Observatory Practice (NMSOP), 1-70, ed. Bormann, P., Potsdam: Deutsches GeoForschungs Zentrum GFZ (2009).

[23] Fuchs, K.; Tittgemeyer, M.; Ryberg, T.; Wenzel, F. and Mooney, W. Global significance of a subMoho boundary layer (SMBL) deduced from high-resolution seismic observations, International Geology Review, 44: 671-685 (2002).

[24] Scrase, F. J. The Reflected Waves from Deep Focus Earthquakes, Proceedings of the Royal Society A: Mathematical, Physical and Engineering Sciences, 132:213-235 (1931).

[25] Stechschulte, V. C. The Japanese earthquake of March 29, 1928. Bulletin of Seismological. Society of America, 22:81-137 (1932).

[26] Beyreuther, M.; Barsch, R.; Krischer, L.; Megies, T.; Behr, Y. and Wassermann, J. ObsPy: A Python Toolbox for Seismology, Seismological Research Letters, 81:530-53 (2010).

[27] Wessel, P.; Smith, W. H. F.; Scharroo, R.; Luis, J. and Wobbe, F. Generic Mapping Tools: Improved Version Released, EOS Trans. AGU, 94; 409410 (2013). 